\title{
Assessing Performance of Three BIM-Based Views of Buildings for Communication and Management of Vertically Stratified Legal Interests
}

\author{
Behnam Atazadeh * (D), Abbas Rajabifard and Mohsen Kalantari \\ The Centre for Spatial Data Infrastructures and Land Administration, Department of Infrastructure Engineering, \\ The University of Melbourne, Parkville, VIC 3010, Australia; abbas.r@unimelb.edu.au (A.R.); \\ mohsen.kalantari@unimelb.edu.au (M.K.) \\ * Correspondence: behnam.atazadeh@unimelb.edu.au; Tel.: +61-383-444-431 \\ Academic Editors: Peter van Oosterom, Efi Dimopoulou and Wolfgang Kainz \\ Received: 31 March 2017; Accepted: 29 June 2017; Published: 3 July 2017
}

\begin{abstract}
Multistorey buildings typically include stratified legal interests which provide entitlements to a community of owners to lawfully possess private properties and use communal and public properties. The spatial arrangements of these legal interests are often defined by multiplexing cognitively outlined spaces and physical elements of a building. In order to support 3D digital management and communication of legal arrangements of properties, a number of spatial data models have been recently developed in Geographic Information Systems (GIS) and Building Information Modelling (BIM) domains. While some data models, such as CityGML, IndoorGML or IFC, provide a merely physical representation of the built environment, others, e.g., LADM, mainly rely on legal data elements to support a purely legal view of multistorey buildings. More recently, spatial data models integrating legal and physical notions of multistorey buildings have been proposed to overcome issues associated with purely legal models and purely physical ones. In previous investigations, it has been found that the 3D digital data environment of BIM has the flexibility to utilize either only physical elements or only legal spaces, or an integrated view of both legal spaces and physical elements to represent spatial arrangements of stratified legal interests. In this article, the performance of these three distinct BIM-based representations of legal interests defined inside multistorey buildings is assessed in the context of the Victorian jurisdiction of Australia. The assessment metrics are a number of objects and geometry batches, visualization speed in terms of frame rate, query time, modelling legal boundaries, and visual communication of legal boundaries.
\end{abstract}

Keywords: building information modelling; stratified legal interests; legal view; physical view; multistorey buildings

\section{Introduction}

\subsection{Background}

The legal boundaries of properties in multistorey buildings are usually difficult to be discerned due to the existence of complex physical structures inside these buildings. Over the last decade, 3D digital data environments have emerged to provide a more communicable method of representing these boundaries for the inexpert community of owners residing in multistorey developments [1]. The basis of structuring, managing and representing 3D data in these environments is underpinned by three distinct types of 3D spatial data models, namely purely legal, purely physical and integrated models. Existing spatial models in land administration, such as Land Administration Domain Model (LADM), mainly focus on the purely legal conception of the built environment, taking less notice of physical aspects [2]. On the other 
side, purely physical notions of buildings are supported by 3D spatial models developed in Geographic Information Systems (GIS) and Building Information Modelling (BIM) domains. The widely known examples of physical models are CityGML [3], IndoorGML [4] and Industry Foundation Classes (IFC) standards [5]. Integrated models enable simultaneous management of both legal and physical aspects of buildings. These models have been developed based on either extending physical models with legal data elements (e.g., [6]) or defining linkages between legal models and physical models [7].

BIM-based approaches are increasingly being used in the Architecture, Engineering and Construction (AEC) sector to enable smart management and operation of buildings [8]. BIM is an intelligent, collaborative, 3D digital model-based process that equips AEC professionals with an integrated approach to more efficiently plan, design, construct, and manage built assets [9]. BIM models provide detailed spatial and semantic information about physical components of buildings, which are architectural, structural and utility elements. It is also possible to manage and represent cognitive spaces, such as a corridor or airspace, inside these models. Interoperability of BIM tools is considered to be a fundamental challenge in the AEC industry [10]. Use of proprietary formats to exchange BIM models typically results in inefficiencies, inconsistencies, repetitions, misinterpretations, and errors over the course of the building lifecycle [11]. To address these issues, the BuildingSMART organization defines and publishes the specifications for the IFC standard, which provides a universal data structure of buildings, facilitating data sharing among BIM tools [12]. However, each proprietary BIM tool implements their own import and export capabilities of IFC format using a different subset of IFC schema. This sometimes results in inconsistency issues in using IFC format to exchange BIM data.

\subsection{Aim}

The main focus of BIM is on modelling physical aspects of buildings. However, it is extendable to manage cognitive notions of built assets such as the legal arrangements of properties. The flexibility of BIM environments provide the ability to define either a purely physical model, or a purely legal model or an integrated legal and physical model of buildings [13]. These models provide three distinct alternatives to manage and communicate legal arrangements of properties in buildings. So far, however, there have been limited investigations about the performance of these three types of 3D digital BIM-based models of buildings. Therefore, the purpose of this article is to evaluate and compare the capabilities of these models using assessment metrics associated with representation, structure and management of legal arrangements of properties in multistorey buildings.

\subsection{Methodology}

The methodology consists of three main phases as explained below:

1. Understanding current practice: For studying the current practice of subdividing legal interests, the Victorian jurisdiction in Australia has been selected. The reason for choosing this jurisdiction is that a wide range of boundaries are used to define spatial extent of legal interests in multistorey building developments. In this phase, two main legal concepts were studied, namely arrangements and boundaries of legal interests. Arrangements refer to defining constituting parts of each legal interest. Boundaries delineate the spatial extent of a part of a legal interest. The identified legal boundaries and legal interests are modelled in BIM environment in the next phase.

2. Implementing models: In this phase, an appropriate multistorey development was selected as a case study. The selected development comprised broad types of legal interests and boundaries. For this development, three distinct BIM models were implemented. These include legal, physical and integrated models.

3. Assessing models: This last phase is dedicated to the assessment of the implemented BIM models using some metrics. The assessment metrics in this study include a number of objects and geometry batches, visualization speed regarding frame per second, query time, modelling legal boundaries, and visual communication of legal boundaries. 


\subsection{Structure}

The next section provides a review of relevant literature on the spatial problems in legal partitioning of buildings as well as 3D spatial data models which are either defined specifically or used potentially for managing legal interests in multistorey buildings. This is followed by a summarized explanation of various boundaries and arrangements used for defining legal interests in current subdivision practices (Section 3). Section 4 provides the logical modelling of legal boundaries in purely legal, purely physical and integrated views of BIM environment. The "Assessment of BIM models" section describes implementation of the BIM models. Moreover, comparisons between these models using the assessment metrics are reported in this section. The last section comprises the main findings of this research and potential directions for future investigations.

\section{Literature Review}

\subsection{Spatial Problems in the Legal Partitioning of Buildings}

In reality, the legal partitioning of buildings is essentially 3D [14]. However, the medium of communication used to represent 3D reality of legal interests in buildings has been mainly predicated on 2D analogue plans. Various countries have proposed different approaches to manage the spatial complexity associated with legal interests in urban built environments [15-18]. This is due to the fact that each country has their own legislative framework, in which they should address problems associated with stratified legal interests. The common spatial problems in visualization and management of legal spaces in buildings include:

- Combining descriptive and 2D plans provided in the deed with 2D parcel boundaries to form a $3 \mathrm{D}$ image of a vertically located legal interest is a very difficult task [1].

- In most cadastral databases, there are no adequate geometric and solid models to store 3D spatial extent of vertically stratified legal objects [19].

- 3D legal objects are only delineated by coordinates and edges on paper plans and it is impossible to check the spatial integrity and validity of these objects [20]. Spatial integrity indicates that 3D legal objects should be volumetrically closed and there should be no gap and undesirable overlap between two legal spaces.

- 3D legal objects are linked to their corresponding land parcel in the cadastral maps in some jurisdictions. Others use a separate database to maintain spatial data about 3D properties [21]. Both approaches result in ambiguous and fragmented representation of 3D legal objects, which affects the authoritative nature of the cadastral maps.

In order to address the above problems, different kinds of 3D spatial data models have been developed. These data models underpin the basis of 3D digital environments. This article is focused on using BIM environment to compare three approaches (purely legal, purely physical and integrated models) in terms of modelling legal interests in buildings. Therefore, existing and potential models (such as CityGML and LADM or integration of these standards), which use similar methods but not essentially in BIM environment, for modelling vertically stratified legal interests will be reviewed in the next subsection. This will position the work presented in this article in a wider context of 3D cadastre field.

\subsection{D Spatial Data Models}

The purpose of managing and representing legal arrangements and boundaries are not specifically considered in purely physical models. However, legal information can be accommodated into these models using their built-in spatial entities and mechanisms for extending them. Purely physical models provide spatial and semantic entities to manage multistorey buildings in different levels of detail. IFC, CityGML and IndoorGML [4,22] standards provide a considerable level of detail to manage information about indoor physical structures and spaces within buildings [23]. Purely legal models are typically developed according to jurisdictional settings, differing from one jurisdiction to another one. 
The concept of legal arrangements is usually communicated via 2D-based and planar representation schemes adopted in these models. Among purely legal models, LADM is one that supports the 3D digital representation of legal information [24]. Therefore, in this section, the relevant literature about IFC, CityGML, and IndoorGML standards (purely physical models), LADM (purely legal model) and integrated (legal and physical) models will be reviewed.

\subsubsection{IFC}

The IFC standard is an open and platform independent data model for storing and managing BIM models [25]. The purpose of this standard is to facilitate interoperability and exchange of BIM models among various BIM platforms. The EXPRESS data modelling language underpins the foundation of this open BIM data model [26]. A comprehensive number of spatial and semantic concepts are used in the IFC standard to enable the entire lifecycle modelling of buildings. From the perspective of spatial sciences, the subclasses of the "IfcProduct" entity describe the geometric and semantic aspects of building elements as well as spatial relationships between these elements [12]. The spatial structure and physical components of a building are hierarchically modelled within the IFC standard (see Figure 1). The order of the IFC hierarchy is "IfcProject", "IfcSite", "IfcBuilding", "IfcBuildingStorey", "IfcSpace" and "IfcBuildingElement" [27]. "IfcProject" provides contextual information about BIM projects such as measurement units, project phase, adopted geometric representations and world coordinate system. "IfcSite" represents the spatial extent of the surface of the land on which buildings are developed. In addition, geographical coordinates, datum elevations, land title number and the address of the construction site can be stored as attributes in this entity. "IfcBuilding" is used for modelling each building and recording information about the address of the building and its elevation from sea level. "IfcBuildingStorey" is used for modelling each building level and elevation of its base relative to the reference height (0.00) of the building. The "IfcSpace" entity describes various kinds of cognitively defined indoor spaces of buildings. "IfcBuildingElement" is a generalized concept for modelling any type of physical building elements. However, specialized entities, such as "IfcWall", "IfcWindow", and "IfcDoor", have been defined to model spatial and semantic aspects of distinct types of physical building elements. The "IfcSpace" entity is a suitable entity for modelling the spatial extent of legal spaces inside buildings. The space boundaries are defined by the "IfcRelSpaceBoundary" entity which not only defines the geometry and topology of a space boundary but also provides the semantic linkage between the physical elements (such as walls and ceilings) and spaces [28]. In other words, this entity provides the ability to query the type of physical structure defining the space boundary.

Besides the hierarchical decomposition of buildings, the IFC standard also supports non-hierarchical approaches to link or reference physical elements and cognitive spaces of buildings in spatial zones. In other words, the concept of spatial zones in IFC defines a non-hierarchical aggregation of building components and spaces for a peculiar purpose such as the thermal activity of the building [29]. This concept can be useful when various parts of a legal interest are in different levels of a building. For instance, a private property typically comprises an apartment unit, carpark, and storage area, which are located in various parts of a building. Therefore, the concept of the spatial zone can be used to establish the linkage between an apartment unit and its carpark or storage area. 


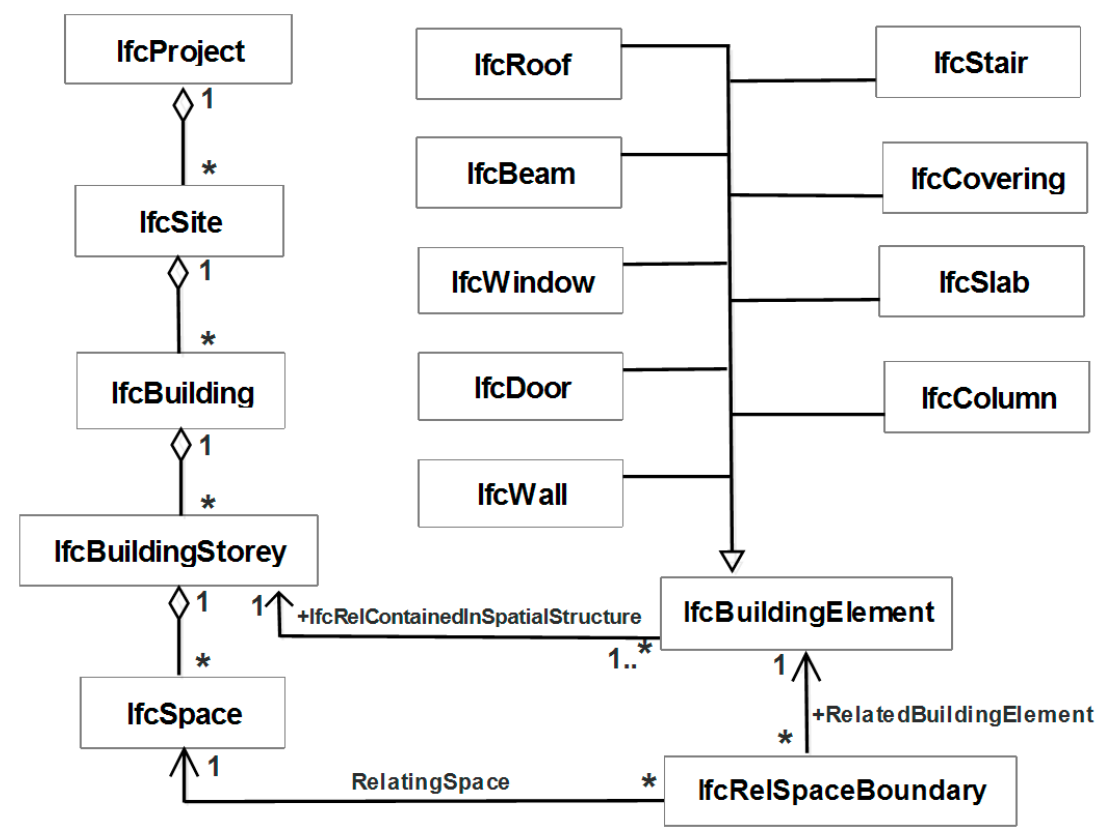

Figure 1. Hierarchical storage of building information in IFC standard.

\subsubsection{CityGML}

The Open Geospatial Consortium (OGC) has defined and promoted the open City Geography Markup Language (CityGML) standard to facilitate interoperability of urban information models [30]. CityGML provides a universal 3D data model for managing semantic, geometric, and topological aspects of urban built and natural environments in both outdoor and indoor scales. CityGML adopts a multi-granular approach to representing 3D urban objects in five Levels of Details (LoD0-LoD4). CityGML is conceptually divided into various modules. Each module comprises entities used for modeling a specific built (such as buildings, bridges, and roads) or natural (such as vegetation and water bodies) urban feature [22]. The building module in CityGML includes entities for modelling architectural structures and spaces of buildings. The fundamental abstract entity in the building module is "_AbstractBuilding", which is specialized into "Building" and "BuildingPart" subclasses (see Figure 2). These instantiable entities are respectively used to model individual buildings and parts of complex building developments. In CityGML, the cognitively defined and non-overlapping indoor spaces are modelled by "Room" entity. Therefore, this entity can potentially be utilized for representing legal spaces inside buildings. Since CityGML uses boundary representation (B-Rep) solid models for storing the geometry of 3D objects, the legal spaces defined by using the "Room" entity are topologically enclosed and valid for cadastral purposes [22]. The semantic boundaries of indoor spaces are also specified through “_BoundarySurface" entity and its instantiable subclasses, namely "WallSurface, InteriorWallSurface, CeilingSurface, FloorSurface, RoofSurface, GroundSurface, OuterCeilingSurface, OuterFloorSurface, and ClosureSurface" (see Figure 2).

These entities are used to define the boundary relationships between a physical structure, such as wall or ceiling, or a virtual element and an indoor space. These spatial relationships can be used to query the location of legal boundaries. However, the existing semantic entities for modelling boundary types in CityGML are limited to specifying only internal and external surfaces of architectural elements. The legal boundaries are sometimes defined in the median location of building elements. For example, a wall between two abutting townhouses is split into two equal parts, each of which belongs to the owner of each townhouse. In some complex situations, the legal boundary can be located in any position inside the physical structure, which is called "other" in the context of Victorian jurisdiction. Modelling the geometry of "median" and "other" is supported in CityGML. Nevertheless, the semantic entities associated with these types of physical boundaries need to be considered in CityGML. One may 
argue that these boundaries can be defined as virtual boundaries (ClosureSurface) because they are defined as imaginary surfaces inside the physical structure. However, we argue that such definition would result in ambiguities in semantic querying of the physical structure associated with the legal boundary. This indicates that the semantic query cannot determine whether the median boundary is defined by a wall or ceiling, although this can be visually observed in the 3D building model.

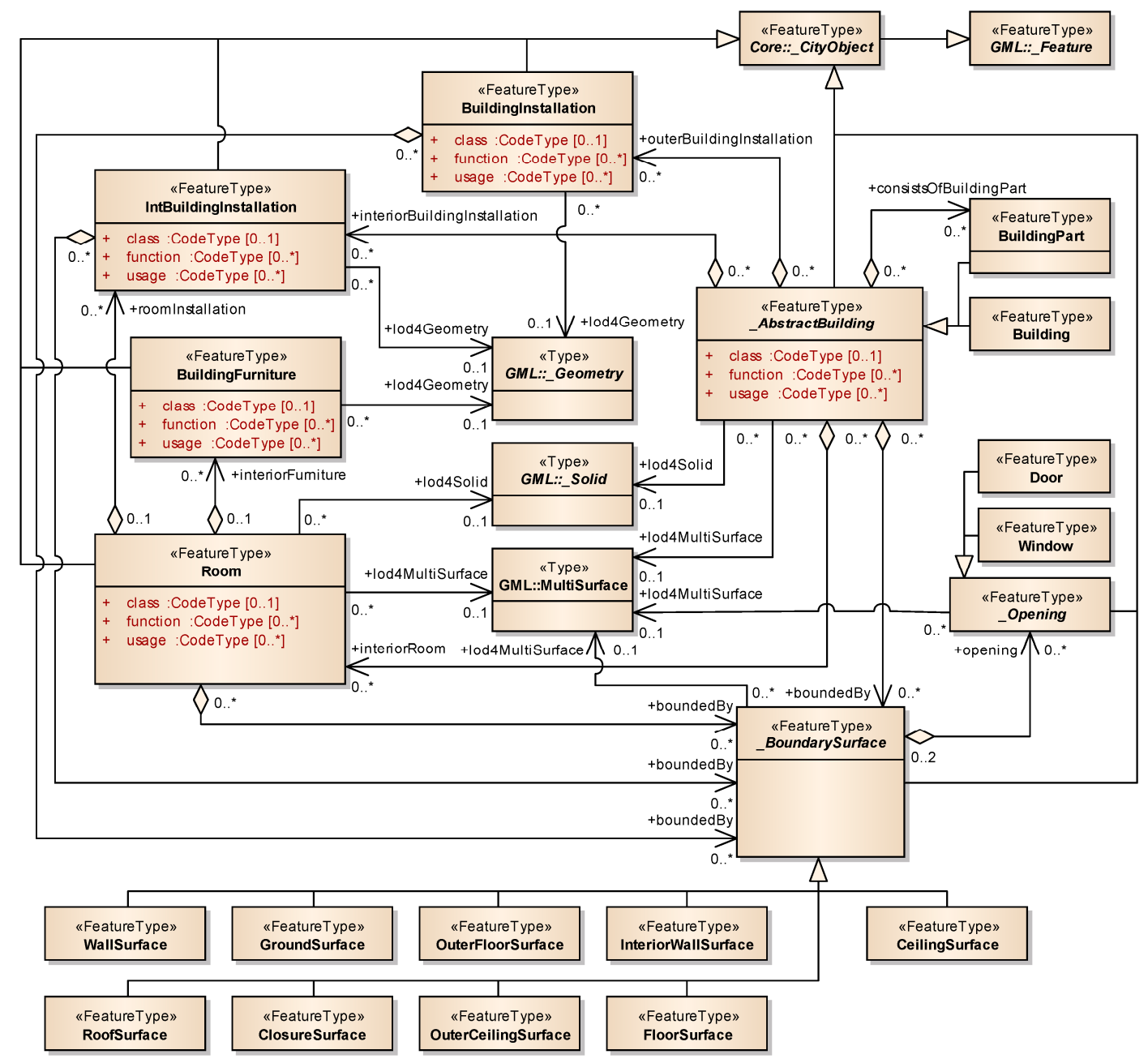

Figure 2. Building model of CityGML, adapted from [31] (p. 57).

Similar to the concept of spatial zones in IFC, CityGML uses the notion of grouping urban objects (CityObjectGroup entity) based on spatial or non-spatial constraints for a peculiar purpose. Various parts of a private or communal property located in different parts of a building can be arranged and grouped using "CityObjectGroup" entity [31]. For example, corridor spaces located in each building level can be grouped into an instance of "CityObjectGroup" to show the entire structure of a common property legal interest in a multistorey building.

\subsubsection{IndoorGML}

IndooGML is a relatively new 3D standard developed by OGC for managing and representing navigation network models of indoor environments [4]. This physical data model comprises fundamental topological and semantic entities required in indoor navigation tasks. Subdivision of indoor spaces and their connectivity and adjacency relationships are supported within IndooGML standard. In this purely physical model, a physical notion of indoor environment is considered to be one space layer. In order to provide indoor navigation services comprehensively, IndoorGML defines 
inter-layer connectivity relationships between space layers. "CellSpace" and "CellSpaceBoundary" are respectively used for modelling indoor spaces and their boundaries. Thus, these entities can be potentially adapted for modelling legal interests and legal boundaries in indoor spaces.

\subsubsection{LADM}

LADM is an ISO standard developed for defining a common ontological reference for communicating legal information in a consistent and effective way among various jurisdictions across the globe [24]. This legal data model lays the foundation for progressive development and enhancement of current land administration systems. The main concepts of LADM are parties, spatial units, basic administrative units, and spatial sources [32] (see Figure 3). Parties refer to people and organizations playing a role in transacting legal interests. Spatial units provide a form of representing legal interests associated with the land, buildings or properties. Common forms of spatial units include areal land parcels or volumetric legal spaces around buildings or utility networks. Basic administrative units are defined based on the arrangement of spatial units associated with the same legal interest. For instance, a private property in a multi-storey building can be considered as one basic administrative unit comprising three spatial units, namely legal spaces of an apartment unit, carpark and storage. Spatial sources refer to data sourcing methods used for delineating boundaries of spatial units. Common examples of spatial sources include field surveys, photogrammetric methods or point cloud data.

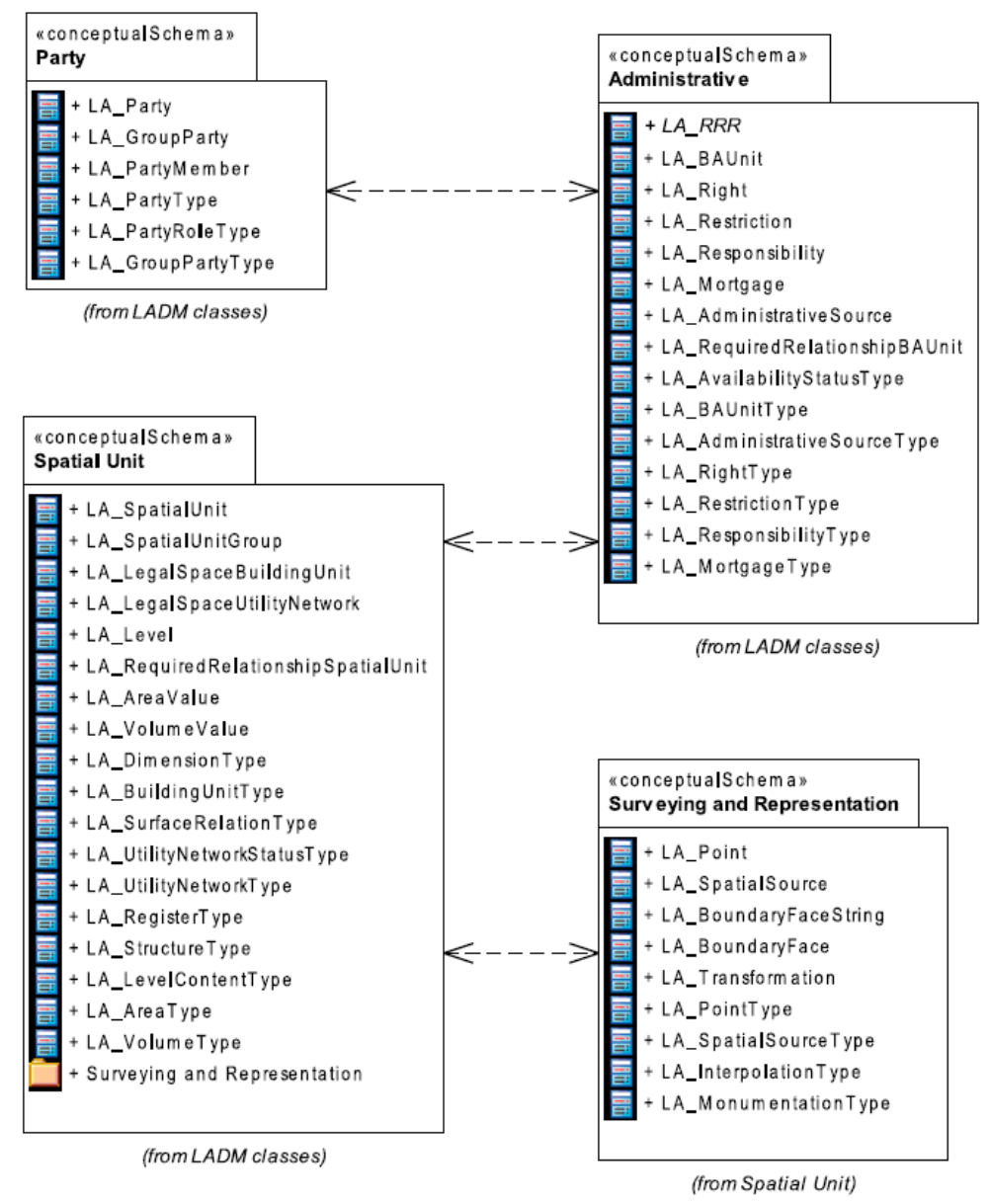

Figure 3. Packages of LADM standard, adapted from [24] (p. 8).

Two concepts are used to define boundaries of spatial units in LADM. The former one is boundary face string which is used to represent either 2D boundaries of areal spatial units or vertical boundary faces of unbounded volumetric spatial units [33]. The latter concept is boundary face which represents 
boundaries of bounded volumetric spatial units [24]. The location of boundary face strings are geometrically defined by at least two points which define the start and end of the boundary line. For boundary faces, a minimum of three points are required to define the geometry since the simplest form of boundary face is a triangle defined by three vertices. In some cases, the "locationByText" attribute is used in LADM to describe the location of boundary face strings and boundary faces in textual rather than geometric terms.

\subsubsection{Integrated 3D Spatial Data Models}

In some jurisdictions around the world (such as Australia), the legal and physical notions of multistorey buildings are linked to each other in design, management and operation phases of these buildings. A purely legal view sufficiently addresses the requirements of subdivision and registration of vertically stratified legal interests. However, when it comes to using legal information for broader purposes such as managing assets during the building lifecycle, a physical representation of buildings plays an important role in unlocking the value of legal information. Additionally, 3D legal interests (cadastral parcels) sometimes exist when there is no physical construction. A good example of this is airspace parcels. Airspaces cannot be spatially represented in the purely physical models. This means that a purely legal or an integrated model should be used in this case. Therefore, there have been some research projects investigating logical interdependencies between legal objects and their physical counterparts. These investigations have adopted two major approaches to defining an integrated 3D spatial data model. One method is to incorporate legal information into physical models using their built-in extension mechanisms, while another technique is to use external links provided in legal models and connect them to physical models.

Integrated models in the GIS domain mainly rely on enriching the CityGML standard using its Application Domain Extension (ADE) mechanism. One of the earliest investigations was done by Dsilva [34] who developed a rudimentary extension of CityGML for managing legal interests. The main incorporated legal data element in his model was "_KadasterApartment" used for managing legal information associated with apartments. Dsilva's proposed extension was more of a purely theoretical model and did not consider details of registration associated with each land parcel. In addition, it does not provide the capability to distinguish privately owned properties with communal ones in buildings. To address these shortcomings, a more advanced ADE of CityGML was developed by Çağdaş [6] to integrate legal and physical information in the context of Turkish jurisdiction. This ADE comprised three legal feature classes, namely "PropertyUnit", "CadastralParcel" and "CondominiumUnit". The "PropertyUnit" class is the abstract superclass for the "CadastralParcel" and "CondominiumUnit" classes. "CadastralParcel" represents legal land parcels which are defined as closed polygons on the Earth's surface. "CondominiumUnit" is used for modelling privately owned properties in buildings. This class has also composition relationships with "JointFacility" and "Annex" classes which represent communal properties used jointly by all and a specific group of owners, respectively. More recently, Li et al. [35] proposed an LADM-based ADE of CityGML aligned with the requirements of Chinese cadastral system. This extension of CityGML was able to model the ownership structures of condominium units inside buildings, reflecting the specifics of spatial relationships between legal objects and physical building elements.

Linking LADM with physical objects is another method to integrate legal and physical information. Soon et al. [7] adopted a semantic-based framework to link LADM elements to those of CityGML. In light of this, the "LA_LegalSpaceBuildingUnit" entity in LADM was externally connected to the "_AbstracBuilding" entity in CityGML.

In the BIM domain, the IFC standard was extended to model legal information using two approaches. In the first method, new subclasses are defined for appropriate IFC entities [19]. For instance, for modelling legal spaces, a new subclass of the "IfcSpace" entity was defined as the "IfcLegalPropertyObject" entity which includes attributes, such as lot liability and lot entitlement, for managing legal interests. The second approach relied upon the existing IFC extension capabilities such 
as property sets and user defined values [29]. In this case, instead of defining subclasses, legal attributes are defined through creating instances of the "IfcPropertySet" entity and attached to the proper IFC entity using "IfcRelDefinesByProperties" objectified relationship. For example, lot entitlement and lot liability attributes can be defined as the "Pset_Lot" property set which can be assigned to the "IfcSpace" entity using the mentioned relationship. All the previous studies published in the topic of using BIM for managing legal interests were mainly focused on development and implementation of the integrated legal and physical BIM models $[2,19,29,36]$. Those investigations have proposed extensions of IFC standard to incorporate legal information within the data schema of this standard. However, these investigations did not provide how well the integrated BIM model can perform in comparison with purely legal and purely physical models. Therefore, the major difference between this investigation and previously published studies is the objective assessment of the integrated BIM model and comparing it with purely legal models and purely physical models using some metrics. This study is a substantially expanded version of the article presented in the fifth 3D cadastre workshop [13].

\section{Overview of Boundaries and Arrangements of Legal Interests in Victoria, Australia}

In Victoria, Australia, two main types of legal interests are applied, namely primary legal interests and secondary legal interests. Primary legal interests are considered as the base level land parcels, which have spatial extent in either 2D or 3D, without any overlap or gap between them. Lots, common properties, roads, reserves, and crown parcels are the primary legal interest defined in the Victorian cadastral system. The secondary legal interests affect the primary ones by providing benefits or imposing restrictions on them. These include easements, restrictions, depth limitations and airspaces. Secondary legal interests can be spatially overlapped with primary legal interests.

Volumetric lots, common properties and easements are the commonly defined legal interests, which have 3D spatial extent inside multi-level building developments (Atazadeh, Kalantari, Rajabifard, Champion, and Ho, 2016). The main focus of this investigation is on those legal interests.

Volumetric lots usually comprise two components, main part and accessory parts. Examples of the main part are an apartment or an office. Accessory parts can be a carpark or a storage area. A typical instance of a volumetric lot is represented in Figure 4.
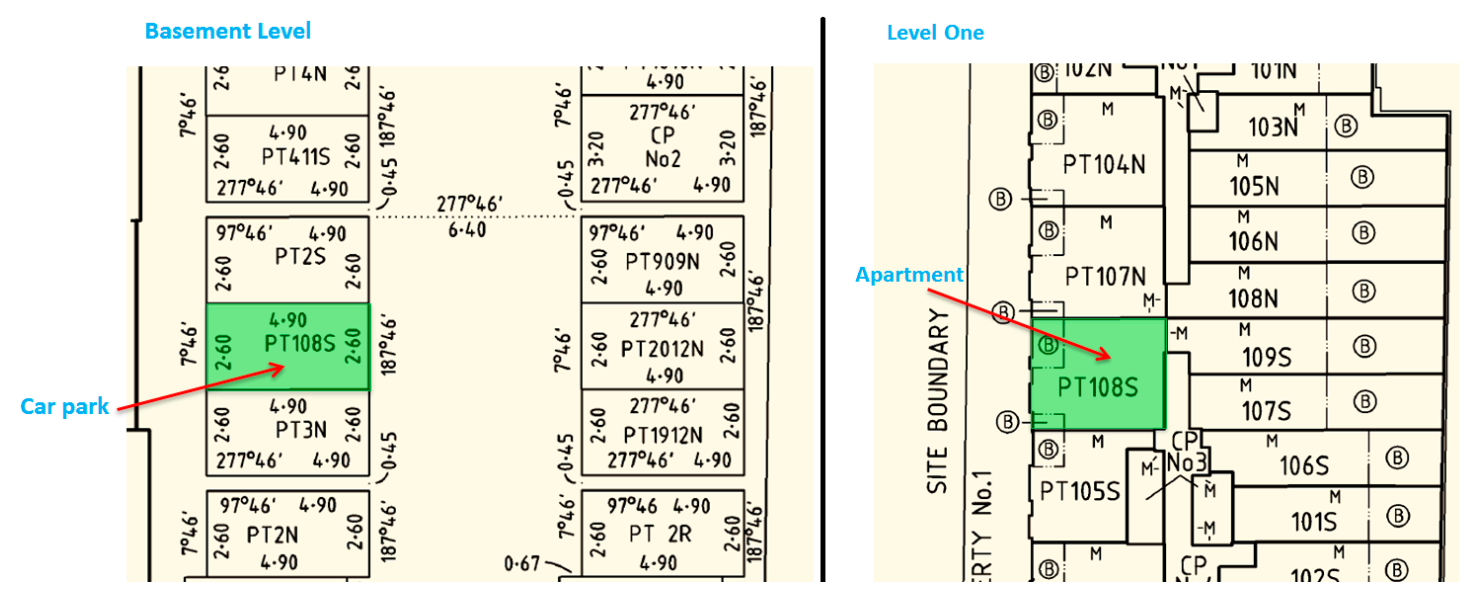

Figure 4. Parts of a volumetric lot.

Common property is defined based on arrangements of indoor or outdoor spaces as well as physical building elements, being more spatially complex than the volumetric lots. In the existing subdivision practices in Victoria, only the spatial extent of communal spaces is represented in 2D floor or cross-sectional plans. Communal building elements are not clearly shown in 2D plans since delineating building elements would result in complexities inside the plans and graphical representation of physical building elements in 2D plans is very difficult. Nevertheless, the notation 
section of plans describes those building elements which are considered as part of the common property interest. For instance, for common property No. 1 (Figure 5), it is indicated in the notation section of the subdivision plan that "All walls defining boundaries, floor and ceiling slabs, columns, internal service ducts, conduits, pipe shafts, and electricity consumer mains cables within the building and courtyards are deemed to be part of common property No.1" (excerpt from a notation section of a subdivision plan).

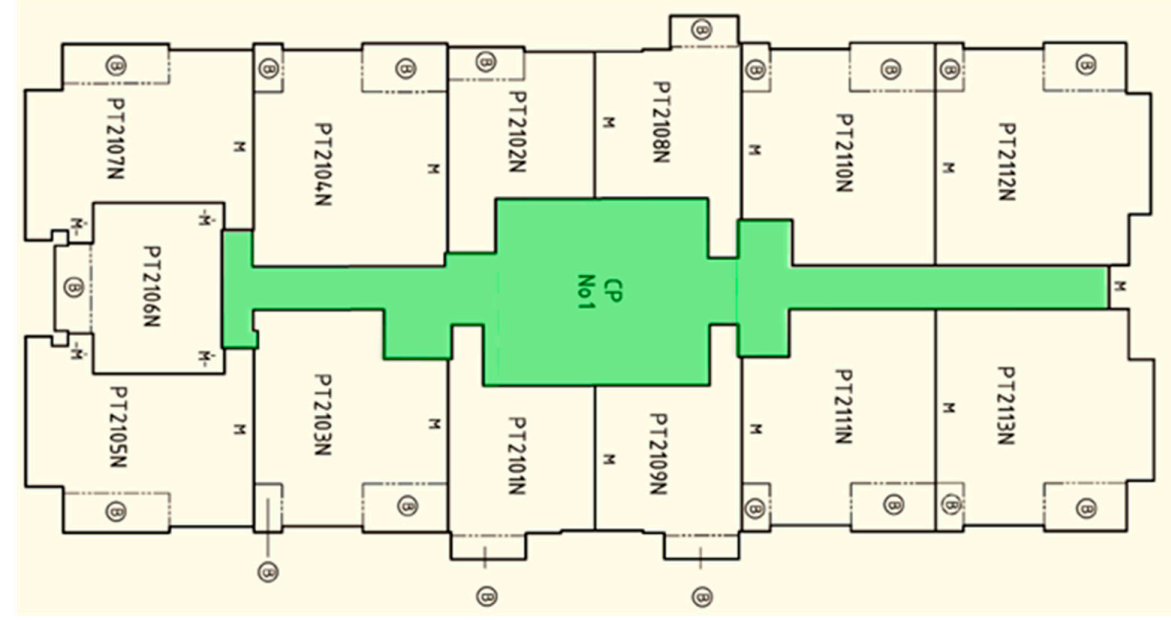

Figure 5. Common property delineated in floor plan diagram.

An easement represents utility networks which provide benefits or pose restrictions on the original land parcel that the building has been developed on (see Figure 6). This legal interest can itself be either physical (visible) elements, such as utility elements outside the buildings and roads, or it can be invisible external spaces surrounding utility elements.

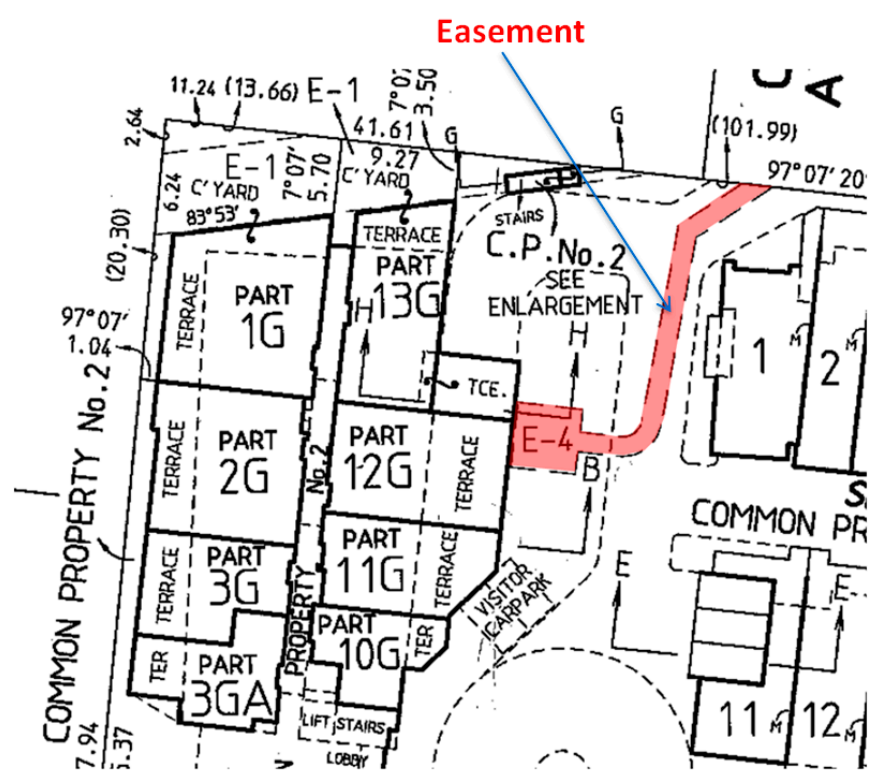

Figure 6. An easement depicted in a plan of subdivision, adapted from [29] (p. 509).

In addition to arrangements of legal interests, legal boundaries defining the spatial extent of each constituting part of the legal interest must be specified. A comprehensive taxonomy of legal boundaries for Victorian cadaster was developed in [2]. This taxonomy reflects an expanded version of the widely known dichotomy between general and fixed boundaries. There are three types of general boundaries, 
namely structural, projected and ambulatory ones. Structural boundaries are mainly defined through referencing the interior, exterior, or median of the physical structure. As an example of structural boundaries, it can be seen in Figures 4 and 5 that median boundaries are notated using the letter " $\mathrm{M}$ ". Projected boundaries are mainly defined in balcony and terraced areas of building through extruding walls and ceilings. Ambulatory boundaries are defined by referencing dynamic natural features, such as rivers [37] (p. 360). Fixed boundaries are defined based on precise surveying measurements.

\section{Legal Partitioning in BIM-Based Views}

In this section, logical definition of legal boundaries and arrangements of ownership spaces in each BIM-based view of buildings will be explained.

\subsection{Purely Legal View}

Figure 7a represents how legal spaces and their boundaries are modelled within a purely legal BIM-based view. First, the building is partitioned into building levels. After that, each building level is partitioned into its constituent legal spaces. For defining each legal space, at least three legal boundaries are required to ensure that it is a closed legal space. Each legal boundary is associated with one or two legal spaces. The "BoundaryPosition" attribute of "Legal_Boundary" entity is used to semantically distinguish various types of legal boundaries such as interior, exterior and median ones.

a)

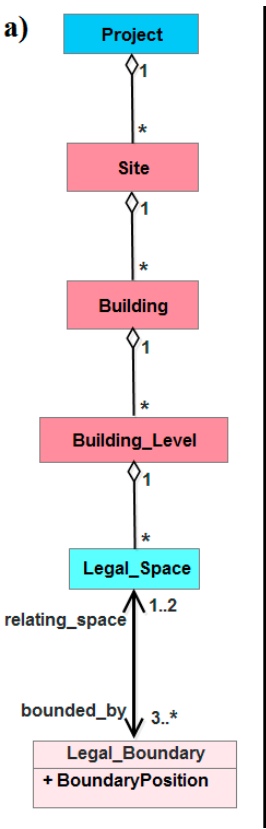

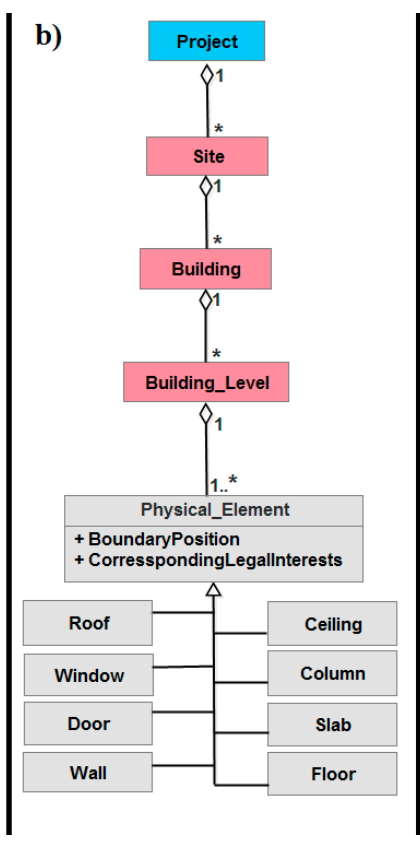

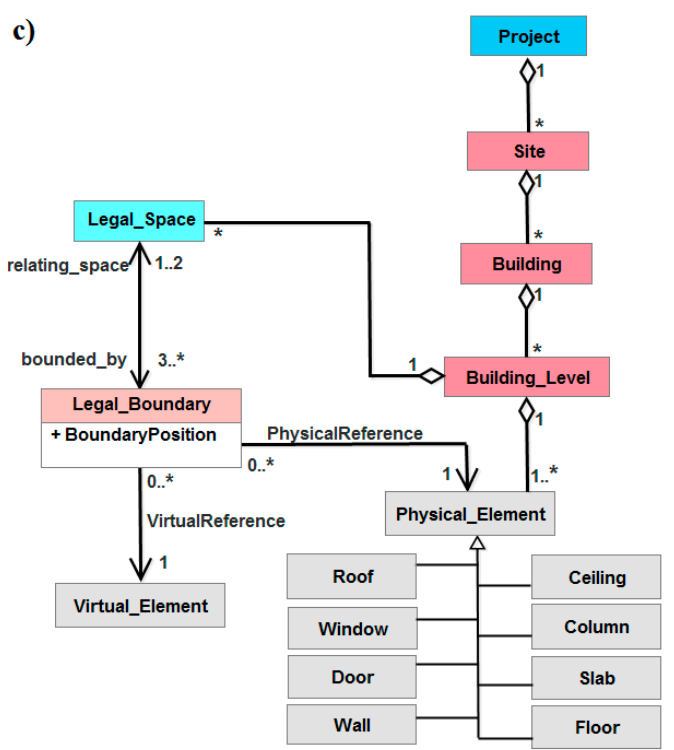

Figure 7. Logical modelling of legal spaces and boundaries in BIM-based views, (a) Purely legal view; (b) Purely physical view; (c) Integrated legal and physical view.

\subsection{Purely Physical View}

Legal partitioning in purely physical view of BIM environment is underpinned by the diagram shown in Figure $7 \mathrm{~b}$. In a purely physical project, the building is partitioned into its levels. Then, each level is constructed based on its constituent physical elements. These physical elements include walls, windows, doors, ceilings, floors, slabs, columns, slabs, and roof. To assign legal interests in the physical model, two new attributes were assigned to each building element: "CorrespondingLegalInterests" and "BoundaryPosition". The "CorrespondingLegalInterests" attribute specifies legal interests which are associated with the building element. The "BoundaryPosition" attribute of "Physical_Element" entity defines whether the exterior or interior face of the building element is used to delineate the legal boundary. 


\subsection{Intergrated View}

Integrated view is composed of both physical elements and legal spaces (see Figure 7c). In these models, after partitioning the building into building levels, both cognitive legal spaces and physical elements are used in legal subdivision of each level. Similar to purely legal views, legal boundaries define the spatial extent of legal spaces in an integrated view of BIM environment. However, it is possible to reference both physical and virtual elements defining legal boundaries. This can be achieved by defining "PhysicalReference" and "VirtualReference" relationships between "Legal_Boundary" entity and "Physical_Element" and "Virtual_Element" entities, respectively. The "BoundaryPosition" attribute of "Legal_Boundary" entity can be used to provide a semantic definition for various boundary types (internal, external, and so on).

\section{Assessment of BIM Models}

In this section, an integrated BIM model is compared with purely legal and purely physical BIM models. In order to create a purely legal BIM model of the development, subdivision plans for this development were used. Only legal spaces were used to define volumetric lots, common properties, and easements within the legal model (see Figure 8a). Architectural plans were used to construct the purely physical model of the development. Various building elements such as walls, ceilings, floors, doors, and windows were constructed (see Figure 8b). The integrated model is constructed by integrating architectural elements, which are created by 2D architectural plans, and legal spaces as well as legal boundaries, which are defined based on subdivision plans (see Figure 8c).

All BIM models were prepared in Autodesk Revit. Since Revit has its own proprietary and closed data format for storing BIM models, all BIM models were converted into open IFC files which can be visualized and queried in any BIM-based platform. The Solibri Model Viewer was used for visualization of BIM models in IFC format. The reason for selecting Solibri Model Viewer was that a recent investigation of BIM visualization tools found that this viewer performs well when compared to other tools [38]. To perform various queries on BIM models, the xBIM toolkit (More details about xBIM is provided on https:/ / github.com/xBimTeam) was used since it provides the ability to query and manipulate IFC files. The specifications of the workstation used for querying and visualizing BIM models included an Intel Core i7 $340 \mathrm{GHz}$ CPU, 4 GB of RAM, AMD Radeon HD 6350 GPU running Windows $7 \times 64$. In order to minimize the effect of other tasks of the operating system on the measurement related to querying and visualization of each BIM model, all user installed processes and applications were shut down. This indicates that the side effects of other tasks were thus minimized and measurements for each BIM model were calculated in similar conditions.

The metrics used for comparing the models included a number of objects and geometry batches, visualization speed (frame per second), query time, modelling legal boundaries, and visual communication of legal boundaries. The number of objects and geometry batches metrics are suggested as appropriate measures for the size and complexity of BIM models [39]. The frame per second (FPS) metric is typically used to measure visualization speed and real-time interaction with BIM models [38]. The query time metric is also an important factor when a user wants to search for and retrieve specific information from BIM models [40]. Modelling and visual communication of legal boundaries metrics are defined to explore the ability of each BIM model in terms of delineating a legal boundary and intuitive understanding of the legal boundary [41,42]. The following subsections provide the measurement results of the assessment metrics for each BIM model. 


\section{a)}
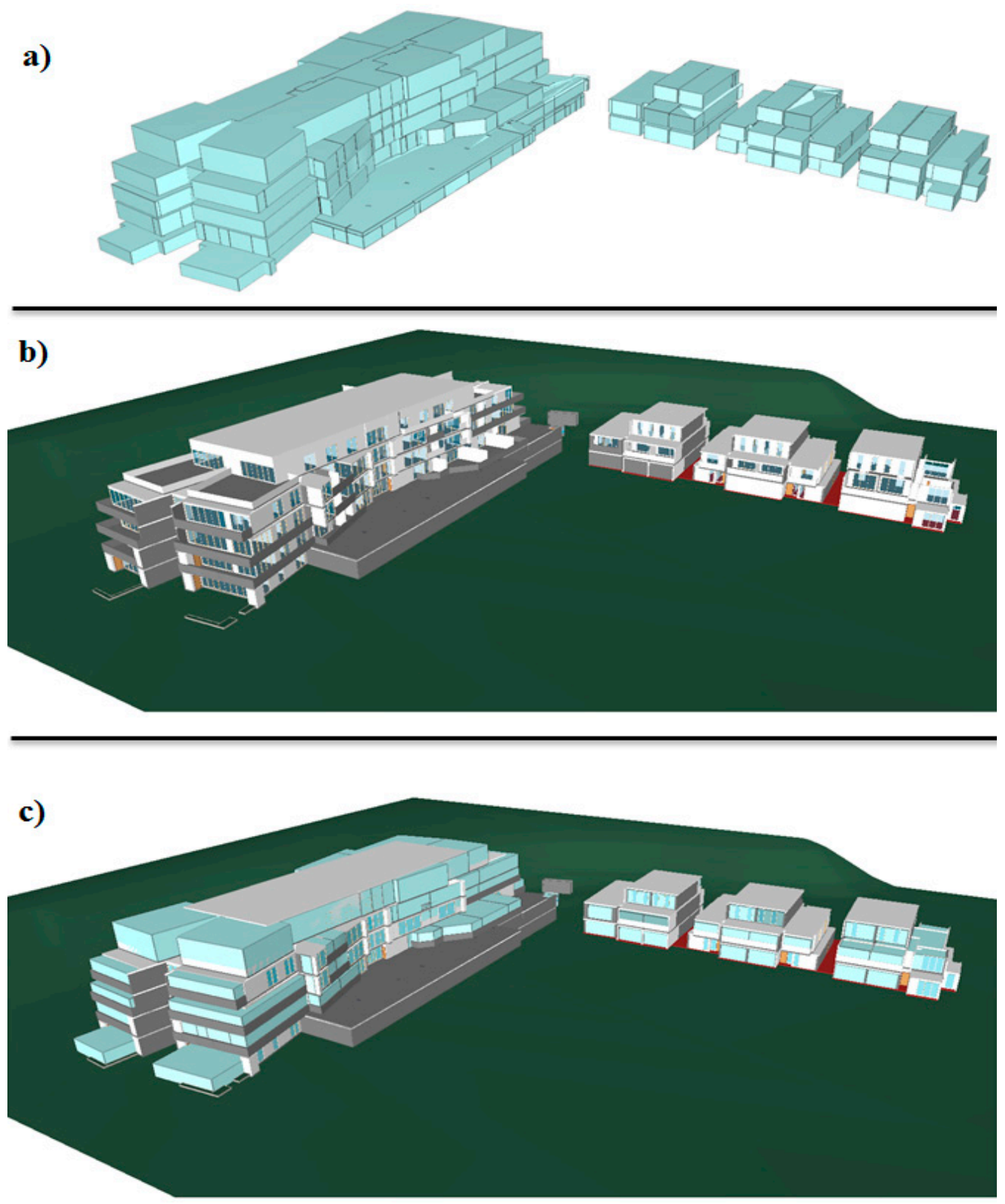

Figure 8. Implemented BIM models: (a) Purely legal model; (b) Purely physical model; (c) Integrated model (In legal and integrated models, the invisible common property space between building and townhouses was not shown for clarity purposes).

\subsection{Number of Objects and Geometry Batches}

In order to measure the number of objects and geometry batches, the xBIM toolkit was used since it provides functions for counting objects and geometry batches within IFC files. Table 1 compares the BIM models in terms of the number of objects and the number of geometry batches. These metrics are used for measuring the size of BIM models. The "Number of objects" metric refers to all spatial objects contained within each BIM model. A geometry batch refers to number of parts constituting each spatial object. For instance, windows are composed of two batches, one for the frame and the other for the glass, while walls typically include one batch. It can be seen in Table 1 that legal BIM model has the minimum size, whereas the largest size belongs to the integrated model. Another result is that there is a considerable difference between the legal model and the physical model in terms of both number of objects and geometry batches. This stems from the fact that one part of a legal interest, 
for example an apartment unit of a volumetric lot, can be spatially defined by only one legal space object (IfcSpace), whereas at least six physical objects, including four walls (IfcWall) and two slabs (IfcSlab), are required to define spatial extent of the same part of a legal interest. This indicates that storing legal models would be easier than physical models.

Table 1. Number of objects and geometry batches in each BIM model.

\begin{tabular}{ccc}
\hline BIM Model & Number of Objects & Number of Geometry Batches \\
\hline Legal model & 173 & 173 \\
Physical model & 1562 & 1954 \\
Integrated model & 1735 & 2127 \\
\hline
\end{tabular}

\subsection{Visualization Speed}

The real time rendering performance of BIM tools is fundamental to interacting with them. Frame rate or frame per second (FPS) represents the visualization and rendering speed of graphical applications. In 3D environments, a threshold FPS value of $15 \mathrm{~Hz}$ is essential for smooth interaction with 3D models. However, an FPS value of around $60 \mathrm{~Hz}$ in highly interactive 3D environments, such as $3 \mathrm{D}$ games, is required to provide smooth interaction with the user. Visualizing and rendering BIM models requires less interactivity compared to gaming environments. Literature suggests that an FPS value of $30 \mathrm{~Hz}$ is acceptable when interacting with BIM models [38]. Most BIM tools, such as the Solibri Model Viewer, provide the ability to view BIM models from various viewpoints. The common viewpoints supported by BIM tools include top, bottom, front, back, right, left, and isometric. Therefore, the minimum, maximum and average FPS values were measured over a 60 second interaction time with each BIM model from each viewpoint. The results are represented as a series of charts in Figure 9. These charts show trends of visualization speed in BIM models as discussed below:

The rendering performance of all BIM models was the smoothest when the models were represented from top viewpoint. From this perspective, the FPS values fluctuated between $35 \mathrm{~Hz}$ and $45 \mathrm{~Hz}$, which is more than the recommended FPS value of $30 \mathrm{~Hz}$.

The isometric viewpoint generated the worst results for all BIM models, resulting in FPS values that were around the essential threshold $(15 \mathrm{~Hz})$. On some occasions, FPS values were lower than $15 \mathrm{~Hz}$ and interaction with all models was not smooth.

From most viewpoints, the FPS values of the physical model were found to be more than those of the legal model, although the number of objects for the physical model is more than the legal model. The largest difference between the FPS values of the purely physical model and those of purely legal and integrated models was observed from the front viewpoint. The smoothest interaction with purely physical models can be explained by the fact that the volume of the 3D space occupied by building elements is less than volume of the legal spaces. Therefore, interacting with the physical model was smoother than the legal model.

The integrated model was the least interactive model compared with the purely legal and purely physical models since the volume of space occupied by this model is the summation of the volumes of both legal spaces and physical building elements. 
Top Viewpoint

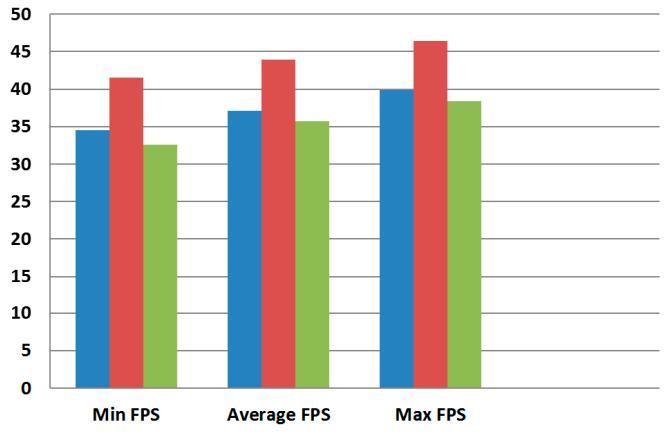

Front Viewpoint

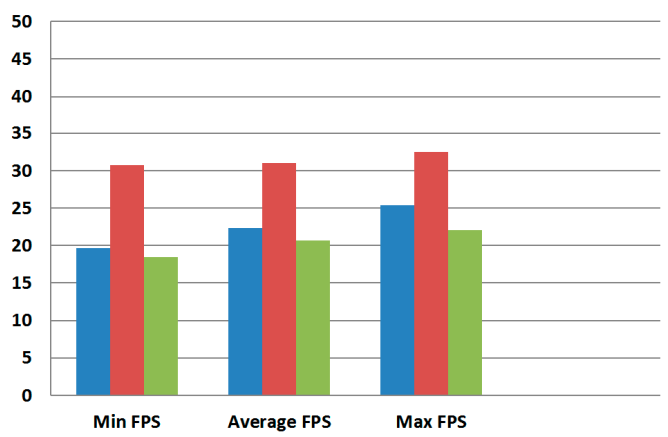

Right Viewpoint

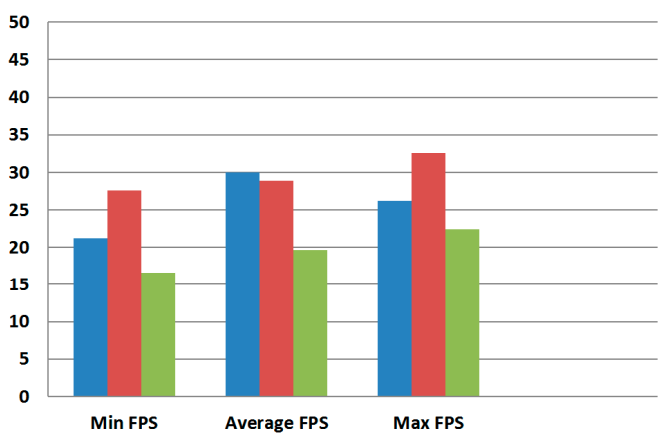

Isometric Viewpoint

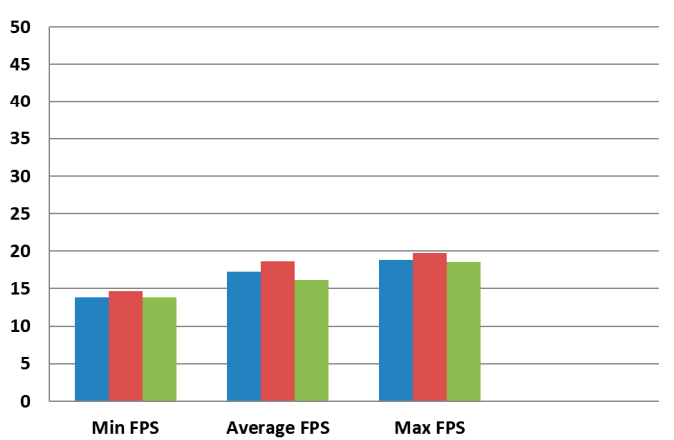

\section{Bottom Viewpoint}

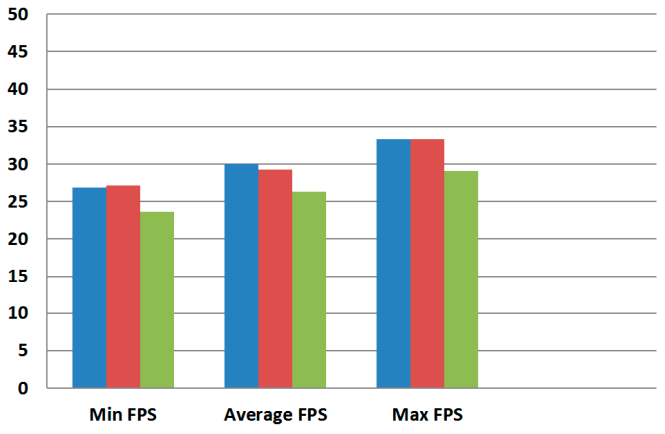

Back Viewpoint

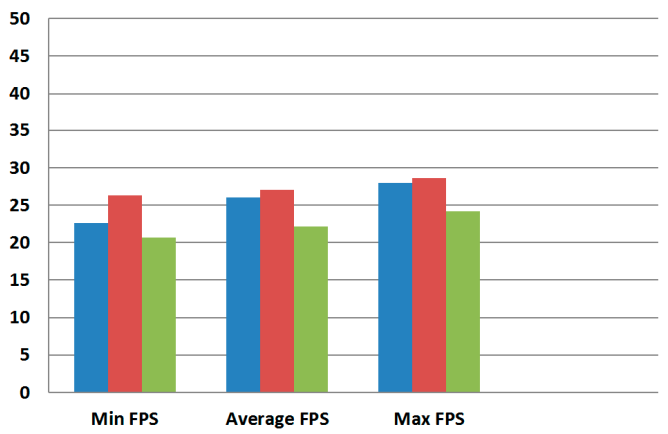

Left Viewpoint

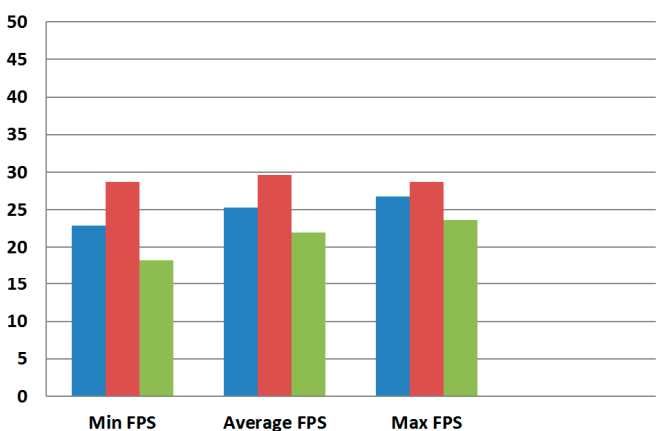

\section{Legal Model}

Physical Model

Integrated Model

Figure 9. Minimum, maximum and average FPS for each model from various viewpoints in Solibri Model Viewer.

\subsection{Semantic Query Time}

Since the selected development includes volumetric lots, common properties and easements, semantic queries for finding these legal interests were executed. Initially, there were significant 
discrepancies in the time measured for these queries. After running queries approximately 30 times, the observed differences between two consecutive runs were insignificant (less than one millisecond). Therefore, there execution of each query was done for another five times. Figure 10 shows the average value of the query execution time for the selected legal interests in each BIM model. Overall, queries in the legal model were executed faster than the physical model. One reason is that because the total number of objects in the legal model was less than in the physical model. Another reason is that while only one legal space is required within the legal model to query a specific part of a legal interest, at least six objects (four walls and two ceilings) are required to query a specific part of a legal interest. Unsurprisingly, querying legal interests took the longest time for the integrated model since it has the largest number of objects. Another result is that the querying time for the common property of the building involves more than strata lots and easements in all BIM models. The reason is that common property is composed of a large number of parts in comparison with strata lots and easements. For example, in an integrated model, a common property includes walls between lots and ceilings between levels, corridors, lobbies, elevators, and stairs, whereas a volumetric lot include a maximum four spaces (apartment unit, storage space, and two car park spaces) and easements typically comprise two parts (such as a utility element and a legal space around that element).

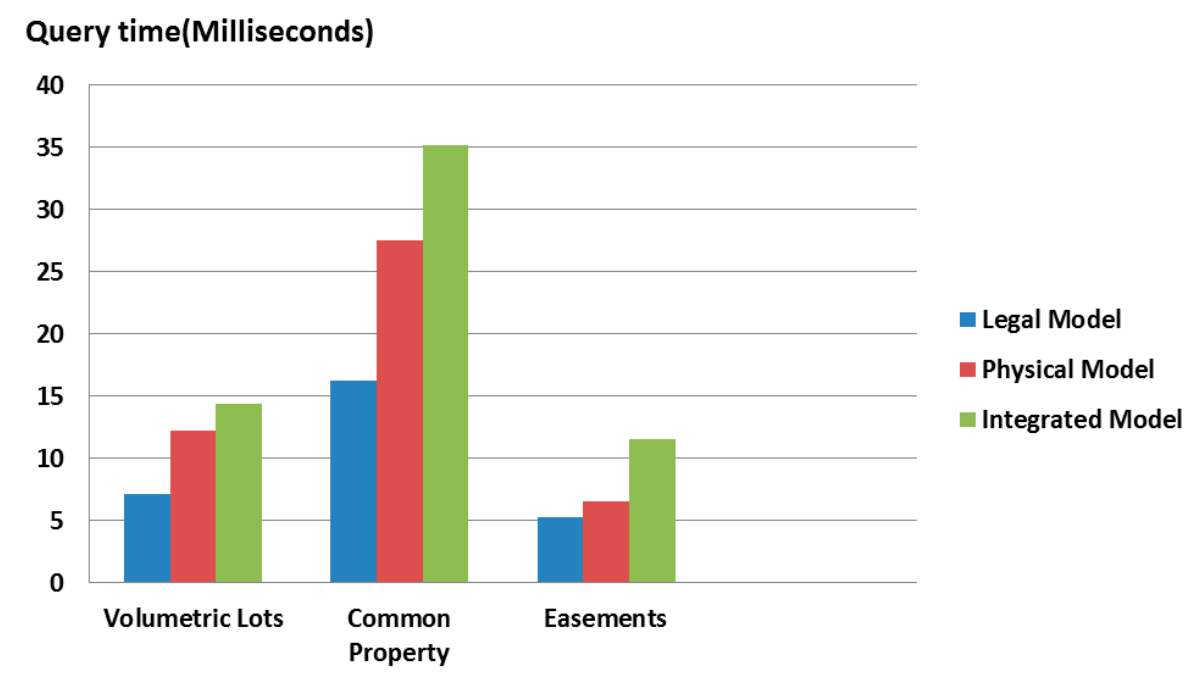

Figure 10. Measured average time for executing semantic queries in BIM models.

\subsection{Managing Legal Boundaries}

For managing legal boundaries, two distinct concepts should be differentiated from each other: modelling and visual communication. Modelling means that a specific boundary type can be stored and recorded within a 3D model irrespective of the approach used for its visualization. Visual communication can be defined as communicating a specific boundary type merely through graphical or image-based representations. The following subsections explain how modelling and visual communication of each legal boundary can be supported in each BIM model.

\subsubsection{Modelling Legal Boundaries}

Table 2 shows the capability of each model for storing and recording different types of boundaries. Both legal and integrated models have the ability to model all sorts of legal boundaries. In contrast, the physical model is only able to model interior and exterior structural boundaries as well as ambulatory ones. Median structural boundaries as well as fixed and projected boundaries do not have a physical manifestation. Therefore, it is impossible to model these boundaries within a purely physical model. 
Table 2. Feasibility of modelling legal boundaries in each BIM model (-: not supported, +: supported).

\begin{tabular}{cccc}
\hline Legal Boundary & Physical Model & Legal Model & Integrated Model \\
\hline Interior structural boundary & + & + & + \\
Median structural boundary & - & + & + \\
Exterior structural boundary & + & + & + \\
Ambulatory boundary & + & + & + \\
Projected boundary & - & + & + \\
Fixed boundary & - & + & + \\
\hline
\end{tabular}

\subsubsection{Visual Communication of Legal Boundaries}

In order to assess each BIM model in terms of visually communicating each boundary type, a human computer interaction experiment was conducted. There were three groups of human subjects, namely 6 students, 6 land administration experts, and 6 BIM experts. In the experiment, the participants were asked to interact with each BIM model and explore different types of legal boundaries defined inside each BIM model in approximately $10 \mathrm{~min}$. Subsequently, the participants responded either "yes" or "no" if they would be able to visually identify a specific legal boundary.

Table 3 shows the results of participants' responses to evaluating the purely legal model. For students, it was difficult to distinguish various types of legal boundaries in the purely legal view of BIM environment since most students did not have adequate expertise in identifying the location of boundaries in this view. In contrast, land administration experts were able to identify interior, exterior, ambulatory, projected and fixed boundaries due to their knowledge of legal boundary definition. However, median boundaries for the majority of land administration experts were difficult to be discerned visually. For BIM experts, only interior and exterior boundaries were visually clear. This is because BIM experts are familiar with constructing internal and external functional spaces and their boundaries. Some examples of legal boundaries defined in the purely legal model were shown in Figure 11.

Table 3. Responses to visual understanding of legal boundaries in the purely legal model.

\begin{tabular}{ccccccc}
\hline \multirow{2}{*}{ Legal Boundary } & \multicolumn{2}{c}{ Students } & \multicolumn{2}{c}{ Land Administration Experts } & \multicolumn{2}{c}{ BIM Experts } \\
\cline { 2 - 7 } & Yes & No & Yes & No & Yes & No \\
\hline Interior structural boundary & 1 & 5 & 4 & 2 & 5 & 1 \\
Median structural boundary & 0 & 6 & 1 & 5 & 1 & 5 \\
Exterior structural boundary & 0 & 6 & 5 & 1 & 4 & 2 \\
Ambulatory boundary & 0 & 6 & 4 & 2 & 2 & 4 \\
Projected boundary & 2 & 4 & 6 & 0 & 1 & 5 \\
Fixed boundary & 1 & 5 & 5 & 1 & 0 & 6 \\
\hline
\end{tabular}

Participants' assessment of the purely physical BIM-based view is presented in Table 4 . All students and BIM experts were able to identify interior, exterior and ambulatory boundaries. Their identification of these legal boundary types was predicated on using physical elements as references for those boundaries. Land administration experts also identified interior and exterior boundaries easily (see Figure 12). However, most of land administration experts expressed that only physical representation of the dynamic natural feature, which is a river in this study, is not adequate enough to communicate ambulatory boundaries since the location of these boundaries change over the period of time. The vast majority of participants confirmed that median, projected, and fixed boundaries are difficult to be understood in the purely physical view of BIM environment. 
Table 4. Responses to visual understanding of legal boundaries in the purely physical model.

\begin{tabular}{ccccccc}
\hline \multirow{2}{*}{ Legal Boundary } & \multicolumn{2}{c}{ Students } & \multicolumn{2}{c}{ Land Administration Experts } & \multicolumn{2}{c}{ BIM Experts } \\
\cline { 2 - 7 } & Yes & No & Yes & No & Yes & No \\
\hline Interior structural boundary & 6 & 0 & 5 & 1 & 6 & 0 \\
Median structural boundary & 2 & 4 & 1 & 5 & 0 & 6 \\
Exterior structural boundary & 6 & 0 & 6 & 0 & 6 & 0 \\
Ambulatory boundary & 6 & 0 & 2 & 0 & 5 & 1 \\
Projected boundary & 0 & 6 & 0 & 6 & 0 & 6 \\
Fixed boundary & 0 & 6 & 0 & 6 \\
\hline
\end{tabular}

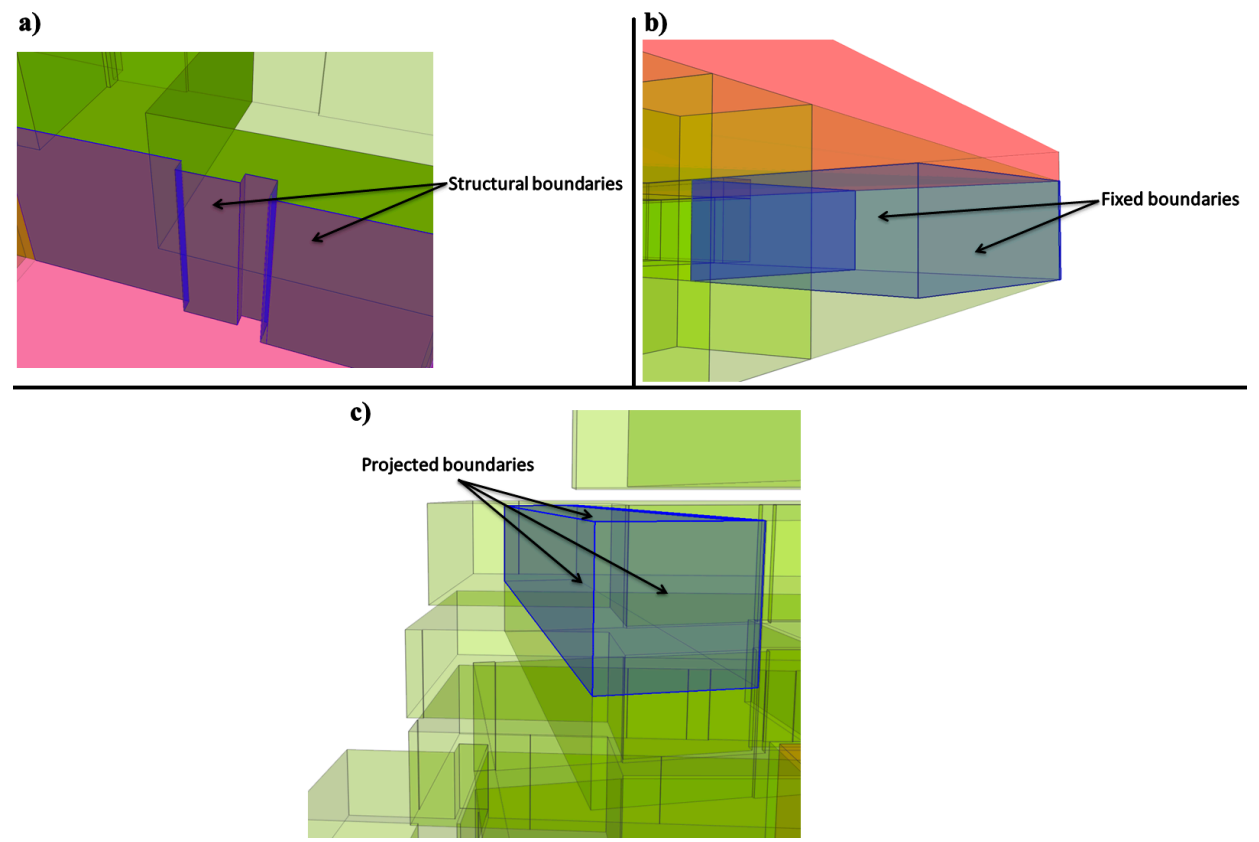

Figure 11. Examples of legal boundaries represented in the purely legal model: (a) Structural boundaries; (b) Fixed boundaries of a parking space; (c) Projected boundaries.

.)

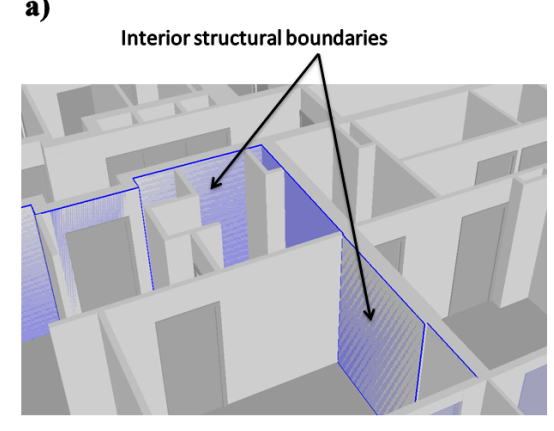

b)

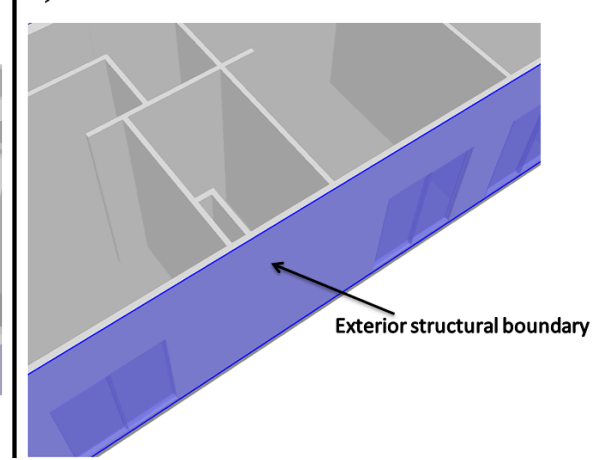

Figure 12. Examples of the legal boundaries represented in the purely physical model: (a) Internal wall boundaries; (b) External wall boundary.

Table 5 provides the results of the subjective assessment of the integrated BIM model. Most participants confirmed that the integrated model provides a clear communication of all legal boundary types since the relationships between physical elements and legal spaces are discernable inside the model. For the vast majority of the subjects, the integration of legal and physical objects was helpful in 
disambiguating the location of structural boundaries, which is mainly assigned as interior, median or exterior face of the corresponding structural element. Although land administration experts do not require physical elements in understanding project and fixed boundaries, they confirmed that those boundaries can be better communicated when physical elements are leveraged in the BIM environment. Figure 13 provides some examples of legal boundaries shown inside the integrated BIM model.

Table 5. Responses to visual understanding of legal boundaries in the integrated model.

\begin{tabular}{|c|c|c|c|c|c|c|}
\hline \multirow{2}{*}{ Legal Boundary } & \multicolumn{2}{|c|}{ Students } & \multicolumn{2}{|c|}{ Land Administration Experts } & \multicolumn{2}{|c|}{ BIM Experts } \\
\hline & Yes & No & Yes & No & Yes & No \\
\hline Interior structural boundary & 6 & 0 & 6 & 0 & 6 & 0 \\
\hline Median structural boundary & 5 & 1 & 4 & 2 & 0 & 6 \\
\hline Exterior structural boundary & 6 & 0 & 6 & 0 & 6 & 0 \\
\hline Ambulatory boundary & 6 & 0 & 6 & 0 & 5 & 1 \\
\hline Projected boundary & 6 & 0 & 5 & 1 & 6 & 0 \\
\hline Fixed boundary & 6 & 0 & 6 & 0 & 6 & 0 \\
\hline
\end{tabular}

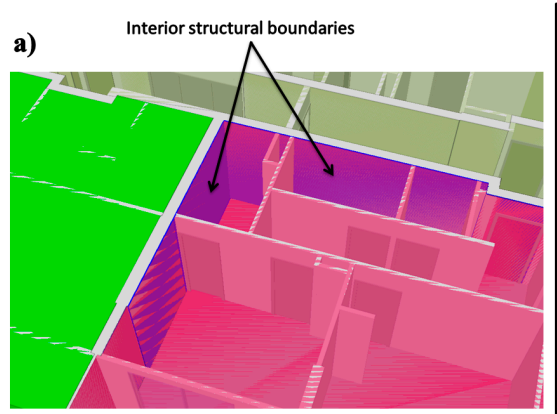

c)

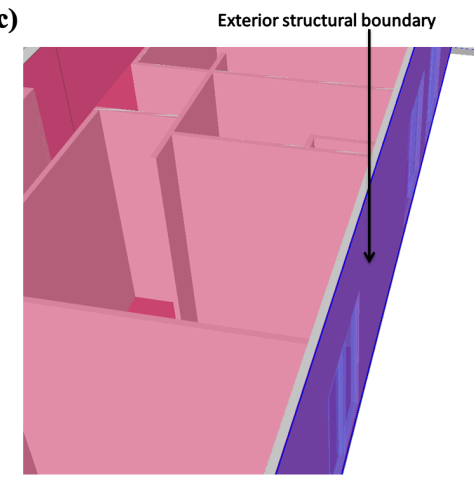

e)

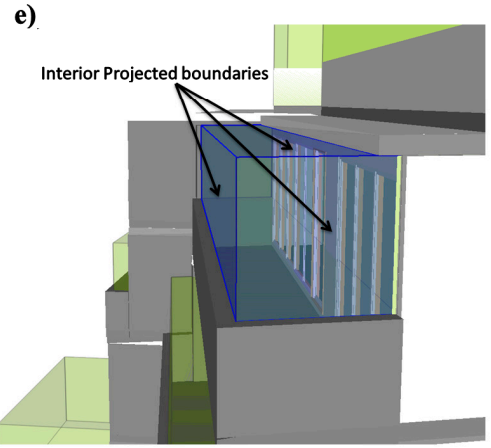

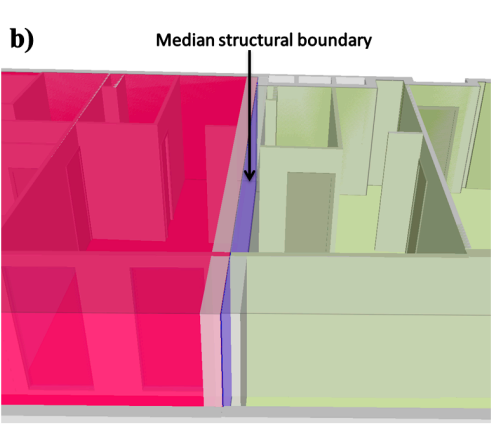

d)

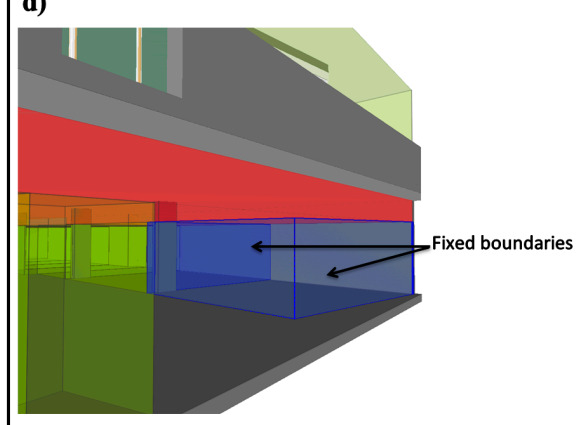

f)

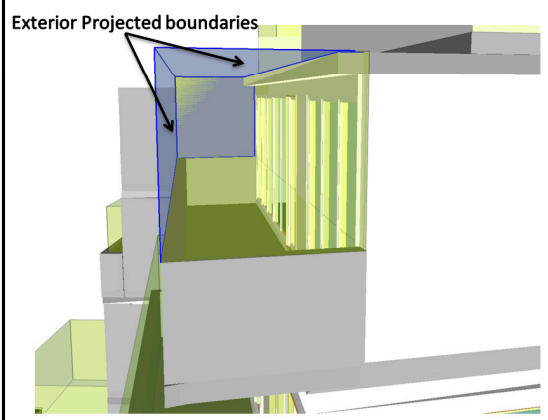

Figure 13. Examples of legal boundaries represented in the integrated model: (a) Internal wall boundaries; (b) Median wall boundary; (c) External wall boundary; (d) Fixed Boundaries of a parking space; (e) Internal projected boundaries; (f) External projected boundaries. 


\section{Conclusions}

This article investigated the performance of three common BIM-based methods, namely purely legal, purely physical and integrated approaches, for storing, managing and communicating legal interests in multistorey buildings. The investigation of current practices in Victoria, Australia showed that a broad range of boundaries and various spatial structures are used to define vertically stratified legal arrangements. The assessment metrics were used to explore the capability of each implemented BIM model. These metrics mainly provided a reflection on the performance of each model in terms of management and communication of legal interests. One finding was that interaction tasks, such as visual inspection and retrieving specific legal interests, in purely legal or physical models was easier to be performed compared to integrated models. It was also found that integrated models provide a more visual communication of the location of legal boundaries, particularly when these boundaries are defined by referencing building elements. This finding indicates that the lay users may find it easier to understand their legal rights in integrated BIM models.

The main focus of this research was on using BIM for multistorey buildings. However, lifecycle information about other built assets, such as roads and bridges, will be considered in future versions of BIM and IFC standard. Therefore, future work could involve investigating the potential capability of the new BIM environment, which comprises both buildings and other urban infrastructure, for managing legal arrangements beyond the spatial extent of multistorey developments. Another important aspect could be investigating the role of legal interests, which are defined in BIM models, for purposes broader than land administration. Since BIM is currently being used in the facility management industry, a BIM model enriched with legal information could pave the way for determining maintenance responsibilities for assets, especially communal facilities, in complex buildings.

Acknowledgments: This work was supported by the Australian Research Council (ARC) [grant number LP110200178].

Author Contributions: This research is a result of collaboration and contribution of all authors. This work is part of the ARC project titled "Land and Property Information in 3D". Abbas Rajabifard is a chief lead investigator of this project. Mohsen Kalantari has a project manager role in the project. Behnam Atazadeh implemented BIM models and conducted the assessments under the supervision and guidance of Mohsen Kalantari and Abbas Rajabifard. Each author had a substantial contribution in the preparation of the manuscript.

Conflicts of Interest: The authors declare no conflict of interest.

\section{References}

1. Stoter, J.; Ploeger, H.; Roes, R.; van der Riet, E.; Biljecki, F.; Ledoux, H. First 3D Cadastral Registration of Multi-level Ownerships Rights in the Netherlands. In Proceedings of the 5th International FIG 3D Cadastre Workshop, Athens, Greece, 18-20 October 2016; pp. 491-504.

2. Atazadeh, B.; Kalantari, M.; Rajabifard, A.; Ho, S. Modelling building ownership boundaries within BIM environment: A case study in Victoria, Australia. Comput. Environ. Urban Syst. 2017, 61, 24-38. [CrossRef]

3. Kolbe, T.; Gröger, G.; Plümer, L. CityGML: Interoperable Access to 3D City Models. In Geo-Information for Disaster Management SE-63; van Oosterom, P., Zlatanova, S., Fendel, E., Eds.; Springer: Berlin/Heidelberg, Germany, 2005; pp. 883-899.

4. Lee, J.; Li, K.J.; Zlatanova, S.; Kolbe, T.H.; Nagel, C.; Becker, T. OGC ${ }^{\circledR}$ IndoorGML; Open Geospatial Consortium: Wayland, MA, USA, 2014.

5. Liebich, T. IFC $2 x$ Edition 3. Model Implementation Guide; Version 2.0.; AEC3 Ltd.: Wycombe, UK, 2009.

6. Çă̆daş, V. An Application Domain Extension to CityGML for immovable property taxation: A Turkish case study. Int. J. Appl. Earth Observ. Geoinform. 2013, 21, 545-555. [CrossRef]

7. Soon, K.H.; Thompson, R.; Khoo, V. Semantics-based Fusion for CityGML and 3D LandXML. In Proceedings of the 4th International Workshop on 3D Cadastres, Dubai, UAE, 9-11 November 2014; pp. 323-338.

8. Heidari, M.; Allameh, E.; de Vries, B.; Timmermans, H.; Jessurun, J.; Mozaffar, F. Smart-BIM virtual prototype implementation. Autom. Constr. 2014, 39, 134-144. [CrossRef] 
9. Azhar, S.; Khalfan, M.; Maqsood, T. Building information modelling (BIM): now and beyond. Constr. Econ. Build. 2015, 12, 15-28. [CrossRef]

10. Isikdag, U.; Aouad, G.; Underwood, J.; Wu, S. Building information models: a review on storage and exchange mechanisms. In Proceedings of the 24th CIB W78 Conference, Maribor, Slovenia, 26-29 June 2007.

11. Bazjanac, V.; Crawley, D.B. The Implementation of Industry Foundation Classes in Simulation Tools for the Building Industry; Building Simulation: Prague, Czech Republic, 1997.

12. Industry Foundation Classes (IFC) for Data Sharing in the Construction and Facility Management Industries; ISO16739; International Organization for Standardization (ISO): Geneva, Switzerland, 2013.

13. Atazadeh, B.; Kalantari, M.; Rajabifard, A. Comparing Three Types of BIM-based Models for Managing 3D Ownership Interests in Multi-level Buildings. In Proceedings of the 5th International FIG 3D Cadastre Workshop, Athenes, Greece, 18-20 October 2016; pp. 183-198.

14. Stoter, J.E.; Van Oosterom, P. Technological aspects of a full 3D cadastral registration. Int. J. Geogr. Inform. Sci. 2005, 19, 669-696. [CrossRef]

15. Guo, R.; Li, L.; Ying, S.; Luo, P.; He, B.; Jiang, R. Developing a 3D cadastre for the administration of urban land use: A case study of Shenzhen, China. Comput. Environ. Urban Syst. 2013, 40, 46-55. [CrossRef]

16. Stoter, J.; Ploeger, H.; van Oosterom, P. 3D cadastre in the Netherlands: Developments and international applicability. Comput. Environ. Urban Syst. 2013, 40, 56-67. [CrossRef]

17. Drobež, P.; Fras, M.K.; Ferlan, M.; Lisec, A. Transition from 2D to 3D real property cadastre: The case of the Slovenian cadastre. Comput. Environ. Urban Syst. 2017, 62, 125-135. [CrossRef]

18. Karabin, M. Registration of untypical 3D objects in Polish cadastre-Do we need 3D cadastre? Geod. Cartogr. 2012, 61, 75-89.

19. Atazadeh, B.; Kalantari, M.; Rajabifard, A.; Ho, S.; Ngo, T. Building Information Modelling for High-rise Land Administration. Trans. GIS 2017, 21, 91-113. [CrossRef]

20. Karki, S. 3D Cadastre Implementation Issues in Australia. Master's Thesis, The University of Southern Queensland, Toowoomba, Australia, 2013.

21. Dimopoulou, E.; Elia, E. Legal aspects of 3D property rights, restrictions and responsibilities in Greece and Cyprus. In Proceedings of the 3rd International Workhsop on 3D Cadatres: Development and Practices, Shenzhen, China, 25-26 October 2012; pp. 41-60.

22. Gröger, G.; Plümer, L. CityGML_Interoperable semantic 3D city models. ISPRS J. Photogramm. Remote Sens. 2012, 71, 12-33. [CrossRef]

23. Kolbe, T.H. BIM, CityGML, and Related Standardization. In Proceedings of the Digital Landscape Architecture Conference 2012, Bernburg/Dessau, Germany, 31 May-2 June 2012.

24. Geographic Information-Land Administration Domain Model (LADM); ISO19152; International Organization for Standardization (ISO): Geneva, Switzerland, 2012.

25. Liebich, T. IFC4 - The New BuildingSMART Standard; buildingSMART Standard: Geneva, Switzerland, 2013.

26. Schenck, D.A.; Wilson, P.R. Information Modeling: The EXPRESS Way; Oxford University Press, Inc.: Oxford, UK, 1994.

27. Benner, J.; Geiger, A.; Leinemann, K. Flexible generation of semantic 3D building models. In Proceedings of the 1st International Workshop on Next Generation 3D City Models, Citeseer, Bonn, Germany, 21-22 June 2005.

28. Ding, L.; Drogemuller, R.; Rosenman, M.; Marchant, D.; Gero, J. Automating Code Checking for Building Designs-DesignCheck; University of Wollongong: Wollongong, Australia, 2006.

29. Atazadeh, B.; Kalantari, M.; Rajabifard, A.; Ho, S.; Champion, T. Extending a BIM-based data model to support 3D digital management of complex ownership spaces. Int. J. Geogr. Inform. Sci. 2017, 31, 499-522. [CrossRef]

30. Groger, G.; Kolbe, T.H.; Nagel, C.; Hafele, K.H. OGC City Geography Markup Language (CityGML) En-Coding Standard; Open Geospatial Consortium: Wayland, MA, USA, 2012.

31. Nagel, C. Spatio-Semantic Modelling of Indoor Environments for Indoor Navigation. Ph.D. Thesis, Technische Universität Berlin, Berlin, Germany, 2014.

32. Lemmen, C.; van Oosterom, P.; Bennett, R. The Land Administration Domain Model. Land Use Policy 2015, 49, 535-545. [CrossRef]

33. Lemmen, C.H.J. A Domain Model for Land Administration; TU Delft, Delft University of Technology: Delft, The Netherlands, 2012. 
34. Dsilva, M.G. A Feasibility Study on CityGML for Cadastral Purposes. Master's Thesis, Eindhoven University of Technology, Eindhoven, The Netherlands, 2009.

35. Li, L.; Wu, J.; Zhu, H.; Duan, X.; Luo, F. 3D modeling of the ownership structure of condominium units. Comput. Environ. Urban Syst. 2016, 59, 50-63. [CrossRef]

36. Atazadeh, B.; Kalantari, M.; Rajabifard, A.; Champion, T.; Ho, S. Harnessing BIM for 3D digital management of stratified ownership rights in buildings. In Proceedings of the FIG Working Week 2016 Recovery from Disaster, Christchurch, New Zealand, 2-6 May 2016.

37. Williamson, I.P.; Enemark, S.; Wallace, J.; Rajabifard, A. Land Administration for Sustainable Development; ESRI Press Academic: Redlands, CA, USA, 2010.

38. Johansson, M.; Roupé, M.; Bosch-Sijtsema, P. Real-time visualization of building information models (BIM). Autom. Constr. 2015, 54, 69-82. [CrossRef]

39. Amor, R.; Jiang, Y.; Chen, X. BIM in 2007-Are we there yet. Proceedings of CIB W78 Conference on Bringing ITC Knowledge to Work, Maribor, Slovenia, 27-29 June 2007; pp. 26-29.

40. Schweizer, R. Spatial BIM Queries: A Comparison between CPU and GPU based Approaches. Bachelor's Thesis, Technische Universit at Munchen Faculty of Civil, Geo and Environmental Engineering, Munich, Germany, 2015.

41. Shojaei, D. 3D Cadastral Visualisation: Understanding Users' Requirements. Ph.D. Thesis, The University of Melbourne, Melbourne, Australia, 2014.

42. Aien, A.; Kalantari, M.; Rajabifard, A.; Williamson, I.; Wallace, J. Towards integration of 3D legal and physical objects in cadastral data models. Land Use Policy 2013, 35, 140-154. [CrossRef]

(C) 2017 by the authors. Licensee MDPI, Basel, Switzerland. This article is an open access article distributed under the terms and conditions of the Creative Commons Attribution (CC BY) license (http:/ / creativecommons.org/licenses/by/4.0/). 